\title{
Spectrum of primary intracerebral haemorrhage in Perth, Western Australia, 1989-90: incidence and outcome
}

\author{
Craig S Anderson, Turab M H Chakera, Edward G Stewart-Wynne, Konrad D Jamrozik
}

\begin{abstract}
In a population based register of stroke (n = 536) compiled in Perth, Western Australia during an 18 month period in $1989-90,60$ cases $(11 \%)$ of primary intracerebral haemorrhage were identified among 56 persons ( $52 \%$ men). The mean age of these patients was 68 (range 23-93) and 46 (77\%) events were first ever strokes. The crude annual incidence was 35 per 100000 , with a peak in the eighth decade, and a male predominance. Deep and lobar haemorrhages each accounted for almost one third of all cases. The clinical presentations included sudden coma $(12 \%)$, headache $(8 \%)$, seizures $(8 \%)$, and pure sensory-motor stroke (3\%). Primary intracerebral haemorrhage was the first presentation of leukaemia in two cases (both fatal) and it followed an alcoholic binge in four cases. $55 \%$ had a history of hypertension. 16 (27\%) patients, half of whom had a history of hypertension, were taking antiplatelet agents, and one patient was taking warfarin. There were only two confirmed cases of amyloid angiopathy. The overall 28 day case fatality was $35 \%$, but this varied from $100 \%$ for haemorrhages in the brainstem to $22 \%$ for those in the basal ganglionic or thalamic region. Other predictors of early death were intraventricular extension of blood, volume of haematoma, mass effect, and coma and severe paresis at onset. Although based on small numbers, these data confirm the heterogeneous nature of primary intracerebral haemorrhage, but they also suggest a different clinical spectrum of this type of stroke in the community compared with the experience of specialist neurological units.
\end{abstract}

(F Neurol Neurosurg Psychiatry 1994;57:936-940)

For many years medical thinking about the aetiology of primary intracerebral haemorrhage (PICH) has been dominated by the influence of chronic hypertension and a characteristic vasculopathy of the penetrating branches of major cerebral arteries called lipohyalinosis. ${ }^{1}$ Since the advent of CT, however, there has been a reappraisal of the pathogenesis for this uncommon but most lethal subtype of stroke. ${ }^{23}$ This instrument has given clinicians the ability to distinguish PICH from cerebral infarction accurately, rather than relying on correlation of the symptoms and signs with the findings at necropsy in the subset of patients for whom such data become available. Moreover, it is now possible to diagnose small, peripheral (lobar) PICHs that might have been misdiagnosed as cerebral infarction in the pre-CT era. ${ }^{4}$ Although hypertension remains the prominent risk factor for PICH, ${ }^{5}$ the frequency of massive ganglionic PICH seems to have diminished over the past few decades corresponding to improved detection and treatment of hypertension. ${ }^{6}$ Whereas cerebral amyloid angiopathy has emerged as an important cause of lobar PICH, various other causes for secondary intracerebral haemorrhage have been recognised, including arteriovenous malformations, recreational drug abuse, antithrombotic agents, and anticoagulation treatment. ${ }^{7}$

Clearly, accurate identification of risk factors that predispose to PICH and the implementation of activities to eliminate or diminish their impact is essential to reduce the mortality and morbidity associated with this condition. Information on the natural history of PICH is also needed so that new treatments can be developed and evaluated. Although several hospital based stroke registries, both overseas ${ }^{8-11}$ and in Australia, ${ }^{12} 13$ have reported the proportional frequencies and risk factors for PICH, they are complicated by selection bias that leads to an emphasis on strokes that are severe and require admission to hospital, and excludes those cases that are rapidly fatal. ${ }^{14}$ Population based studies, on the other hand, can provide the necessary data for planning prevention programmes for cerebrovascular disease, but due principally to methodological difficulties there is a scarcity of such information. ${ }^{4-614-18}$ The present study, part of a large, population based study of cerebrovascular disease in Perth, Western Australia, was undertaken to describe the incidence and outcome of PICH.

\section{Methods}

All cases of PICH were drawn from the register of acute cerebrovascular events compiled as part of the Perth Community Stroke Study, which operated during an 18 month period in 1989-90. As described in detail elsewhere, ${ }^{14} 19$ the Perth Community Stroke Study attempted to identify and document every case of stroke and transient ischaemic attack affecting residents of a geographically defined segment of Perth, Western Australia. Multiple overlapping sources were used to ascertain 
cases and included attendances at, and admissions to, all acute hospitals, rehabilitation centres, and nursing homes in and around the study area, coroner's reports and death certificates, and surveillance of computerised hospital discharge statistics that cover all inpatient separations from every hospital in the state. Based on the Australian Bureau of Statistics 1986 census, the estimated population of the study area (at 30 June 1989) was 138708 persons, 69008 men, and 69700 women. All patients on the register met the World Health Organisation clinical criteria for acute stroke: "rapidly developing symptoms and/or signs of focal, and at times global (refers mainly to subarachnoid haemorrhage) loss of cerebral function, with symptoms lasting more than 24 hours or leading to death, with no apparent cause other than that of vascular origin." 20

For each case, a neurology registrar (CSA) recorded clinical details, usually by personal interview (median delay of five days from onset) and then reviewed the relevant CT or MRI films, or necropsies, or both with a neuroradiologist or neuropathologist who was associated with the study. We applied criteria that combined clinical data with the results of cerebral imaging or necropsy so that $86 \%$ of the 536 stroke events on the register could be classified into several pathologically distinct subtypes. The criteria for these specific subtypes have been published. ${ }^{14}$ Briefly, the subtypes identified were types of cerebral infarction-namely, large artery occlusive, embolic, lacunar, and boundary zone-PICH, and subarachnoid haemorrhage. Where there was neither brain imaging nor necropsy, the strokes were defined as being of undetermined type. A PICH was defined as an acute stroke in which necropsy or CT demonstrates the origin of haemorrhage as the cerebral parenchyma. Traumatic intracerebral haemorrhage, haemorrhagic transformation of a cerebral infarct, and haematoma associated with a ruptured aneurysm were excluded by further investigations such as repeat brain imaging or cerebral angiography.

Each brain region that contained haemorrhage was recorded and the origin classified into one of the following sites: deep (caudate, putamen, globus pallidus, thalamus, internal capsule, and deep periventricular white matter); lobar (specific cortical and subcortical locations); cerebellar; and brainstem. Cases of large haemorrhage where it was impossible to distinguish between deep and lobar regions as the site of origin, or to localise a haematoma to a specific cortical lobe, were classified as massive cortical or subcortical haemorrhage. The volume of each haemorrhage was estimated by multiplying the greatest sagittal, transverse, and coronal measures from the CT or brain slices, and graded as mild $(<50$ $\left.\mathrm{cm}^{3}\right)$, moderate $\left(50-100 \mathrm{~cm}^{3}\right)$, or massive $\left(>100 \mathrm{~cm}^{3}\right)$. Mass effect was quantified according to whether or not there was compression of surrounding structures and midline shift of the pineal or septum pellucidum. The presence of intraventricular haemorrhage and hydrocephalic dilatation of the cerebral ventricles was recorded.
Information obtained from each patient at baseline included data on associated illnesses, risk factors for cardiovascular diseases, and the patterns of disability within the immediate premorbid period. If the patient was unconscious or otherwise not assessable, information was obtained from the patient's closest relative or another reliable proxy, hospital records, or the general practitioner, or from the necropsy report when this was the only information available. Level of consciousness at onset was measured by the Glasgow coma scale. ${ }^{21}$ Degree of paresis was measured with the motricity index, ${ }^{22}$ which gives a score from 0 (total plegia) to 100 (normal). We defined a score of $0-50$ as severe paresis, and $51-94$ as moderate paresis, and a score of $95-100$ as normal or minimal paresis. Subjects were classified as hypertensive if they had a clinical history of hypertension or had two or more previously documented systolic blood pressures $\geqslant 160 \mathrm{mmHg}$ or diastolic blood pressures $\geqslant 95 \mathrm{mmHg}$. Information was obtained about use of aspirin, non-steroidal anti-inflammatory agents, and anticoagulants. Consumption of alcohol was assessed via a retrospective diary of drinking on each day of the week preceding the stroke; a binge was defined as $\geqslant 10$ times the usual daily intake.

The same investigator who made the baseline assessments prospectively followed up patients at four and 12 months after the index event or to the time of death if it occurred before one year. For this paper, four month survivors were classified as independent or dependent according to the Barthel index of activities of daily living. ${ }^{23}$

The estimated population of the study area at 30 June 1989 according to the 1986 Australian census served as the denominator for calculating age and sex specific incidence rates. Incidence rates for $\mathrm{PICH}$ refer to all events, rather than patients, and include patients with and without a history of stroke (either ischaemic or haemorrhagic). Rates for first ever PICH have been reported previously. ${ }^{14}$ Rates are reported with $95 \%$ confidence intervals (95\% CIs) and standardised to the world population of Segi, ${ }^{24} 15$ years and over. Odds ratios (ORs) are used as estimates of relative risks and the $\chi^{2}$ test was used in comparisons of proportions. Probability values of $\leqslant 0.05$ were considered statistically significant.

\section{Results}

The Perth Community Stroke Study register included a total of 536 events that met the World Health Organisation criteria for stroke. Of these, $60(11 \%)$ cases were cases of PICH and these occurred among 56 patients $(52 \%$ men). The mean age was 68 (range 23-93) and $46(77 \%)$ events were first ever in a lifetime (first ever) strokes. PICH was confirmed by CT (in $80 \%$ ) or necropsy $(20 \%) ; 20 \%$ had both investigations. The median delay between the onset of symptoms and CT was four (range 1-15) days.

Table 1 outlines selected presenting features of these cases of PICH. Transient 
Table 1 Selected clinical presentations of primary intracerebral haemorrhage *

Baseline variable $n(\%)$

Paresis $52(87)$

Altered consciousness 43 (72)

Sudden coma as first

symptom

Headache

Seizures

Preceding TIA 2 (3)

Stuttering onset

(days)

$3(5)$

*Variables are not mutually exclusive. $\quad$ TIA $=$ transient ischaemic attack.

Table 2 Age and sex specific annual incidence per 100000 population of primary intracerebral haemorrhage in Perth, Western Australia, 1989-90

\begin{tabular}{|c|c|c|c|c|c|c|c|c|c|}
\hline \multirow[b]{2}{*}{$\operatorname{Age}(y)$} & \multicolumn{3}{|c|}{ Men } & \multicolumn{3}{|c|}{ Women } & \multicolumn{3}{|c|}{ Total } \\
\hline & $n$ & Rate & $(95 \% C I)$ & $n$ & Rate & $(95 \% C I)$ & $n$ & Rate & $(95 \% C I)$ \\
\hline $\begin{array}{l}15-54 \\
55-64 \\
65-74 \\
75-84 \\
85+ \\
\text { Total } \\
\text { Standardised rate* }\end{array}$ & $\begin{array}{r}6 \\
9 \\
11 \\
2 \\
3 \\
31\end{array}$ & $\begin{array}{r}9 \\
83 \\
174 \\
58 \\
451 \\
36 \\
34\end{array}$ & $\begin{array}{l}(0-18) \\
(17-150) \\
(48-300) \\
(0-158) \\
(0-1007) \\
(21-52) \\
(20-48)\end{array}$ & $\begin{array}{r}2 \\
1 \\
6 \\
16 \\
4 \\
29\end{array}$ & $\begin{array}{r}3 \\
10 \\
75 \\
.276 \\
222 \\
33 \\
17\end{array}$ & $\begin{array}{l}(0-9) \\
(0-33) \\
(1-148) \\
(111-442) \\
(0-488) \\
(18-48) \\
(7-27)\end{array}$ & $\begin{array}{r}8 \\
10 \\
17 \\
18 \\
7 \\
60\end{array}$ & $\begin{array}{r}6 \\
48 \\
118 \\
196 \\
284 \\
35 \\
25\end{array}$ & $\begin{array}{l}(1-12) \\
(11-84) \\
(49-187) \\
(85-306) \\
(26-541) \\
(24-46) \\
(13-37)\end{array}$ \\
\hline
\end{tabular}

* Standardised to the world population, 15 years and over, by the direct method. ${ }^{24}$

ischaemic attacks preceded a PICH by several months in one case (normal CT performed within one week of onset), and one week in another case (CT not performed). A stuttering onset to the PICH occurred in three cases; one over a month and the other two over several days. Two patients were found dead and had coroner's necropsy examinations. Five cases were managed entirely outside an acute hospital. No case had surgical evacuation of the PICH.

Table 2 shows the age and sex specific annual incidence for PICH in this population. The total crude annual incidence was 35 (95\% CI 24-46) per 100000 population. Although the $95 \%$ CIs for the sex specific rates were wide and overlapped because of the small numbers, the rates generally increased with age.

Table 3 outlines the site of localisation of PICH. Deep and lobar haemorrhage each accounted for almost one third of the events.

Table 3 Localisation of primary intracerebral haemorrhage

\begin{tabular}{lc}
\hline Anatomical localisation & $n(\%)$ \\
\hline Deep & $18(30 \cdot 0)$ \\
Capsulolenticulothalamic & 8 \\
Capsulolenticular & 3 \\
Thalamic & 4 \\
Caudate nucleus and putamen & 3 \\
Lobar & $19(31 \cdot 7)$ \\
Frontal & 5 \\
Parietal & 8 \\
Occipital & 1 \\
Temporal & 4 \\
Corona radiata & 1 \\
Massive cortical/subcortical & $13(21 \cdot 7)$ \\
Frontotemporal & 1 \\
Frontotemporal + parietal & 1 \\
Frontoparietal & 1 \\
Temporoparietal & 2 \\
Parieto-occipital & 4 \\
Frontoparietal + temporo-occipital & 4 \\
Cerebellum & $6(10 \cdot 0)$ \\
Brainstem & $4(6 \cdot 7)$ \\
Total & 60100 \\
\hline
\end{tabular}

Table 4 Outcome according to the site of primary intracerebral haemorrhage

\begin{tabular}{lccccc}
\hline & \multicolumn{2}{c}{ Dead at 28 days } & & \multicolumn{2}{c}{$\begin{array}{l}\text { Dead or disabled } \\
\text { at four months }\end{array}$} \\
\cline { 2 - 3 } \cline { 5 - 6 } Site & $n$ & $\%(95 \%$ CI) & & $n$ & $\%(95 \%$ CI) \\
\hline Brainstem $(\mathrm{n}=4)$ & 4 & 100 & & & \\
Massive cortical $(\mathrm{n}=13)$ & 7 & 54 & & 11 & 85 \\
Deep $(\mathrm{n}=18)$ & 4 & 22 & & 14 & 78 \\
Lobar $(\mathrm{n}=19)$ & 4 & 21 & & 13 & 68 \\
Cerebellum $(\mathrm{n}=6)$ & 2 & 30 & & 3 & 50 \\
Total $(\mathrm{n}=60)$ & 21 & $35(23-47)$ & & 45 & $75(64-86)$ \\
\hline
\end{tabular}

*Disability calculated according to the Barthel index of activities of daily living.
A PICH was the first presentation of acute leukaemia (hypocoagulable states) in two patients, both rapidly fatal. In the remaining 58 cases, $32(55 \%)$ had a history of hypertension but only $15(27 \%)$ were taking antihypertensive medication at the time of the stroke. The proportional frequency of a history of hypertension did not vary significantly between deep (61\%), lobar (56\%), cerebellar/brainstem $(70 \%)$, and massive cortical $(33 \%)$ events $\left(\chi^{2}{ }_{4}=4 \cdot 5, p=0.34\right)$. Sixteen patients $(27 \%)$ were taking either aspirin or a non-steroidal anti-inflammatory agent, and half of this group had a history of hypertension. Only one (fatal) case involved anticoagulation treatment (warfarin), for a prosthetic mitral valve; there was also a history of hypertension and of a previous ischaemic stroke in this instance. The proportion of patients taking either an antiplatelet agent or anticoagulants before a first ever stroke was significantly less for PICH $(8 / 46(17 \%))$ than for ischaemic stroke $(90 / 259(35 \%))\left(\chi_{2}{ }_{2}=5 \cdot 4\right.$, $\mathrm{p}=0.02)$. Four cases of PICH presented after atcoholic binges; all were hypertensive at onset but only one required long term antihypertensive treatment. The prevalence of other defined risk factors for cerebrovascular disease were current smoker $29 \%$, ex-smoker $(>12$ months) $19 \%$, peripheral vascular disease $10 \%$, ischaemic heart disease $7 \%$, and diabetes mellitus $2 \%$. There were only two confirmed (necropsy) cases of amyloid angiography but this was the suspected underlying aetiology in 19 (33\%) other cases; all presented with lobar haemorrhage without a history of hypertension.

Table 4 presents data on the outcome from PICH. The overall 28 day case fatality was $35 \%(95 \%$ CI $23-47 \%)$, but this varied according to the site of haemorrhage (brainstem $(100 \%)$; massive cortical $(54 \%)$; cerebellum $(30 \%)$; deep (22\%); and lobar $(21 \%))$. The prognosis for these sites showed significant heterogeneity $\left(\chi^{2}{ }_{4}=12 \cdot 4, \quad \mathrm{p}=\right.$ 0.01 ). Two thirds of all deaths within the first month occurred during the first four days after onset of PICH. Seventy five per cent (95\% CI $64-86 \%)$ of patients were either dead or disabled by four months after the onset of symptoms. Although the numbers are small, the tendency was for PICH in the brainstem to be the most lethal, whereas those in the cerebellum were the least disabling. Table 5 outlines several variables identified by 
Table 5 Univariate predictors of 28 day mortality

\begin{tabular}{lllrrr}
\hline Variable & $\beta$-coefficient & $S E$ & $p$ Value & OR & $95 \%$ CI \\
\hline Clinical: & & & & & \\
$\quad$ Loss of consciousness & 2.601 & 1.09 & 0.017 & 13.5 & $1.6-113.0$ \\
$\quad$ Severe paresis & 2.381 & 0.85 & 0.005 & 10.8 & $2.0-57 \cdot 2$ \\
$\quad$ Incontinence & 3.045 & 1.08 & 0.005 & 21.0 & $2.5-175.4$ \\
Pathology: & & & & & \\
$\quad$ Mass effect & 1.992 & 0.71 & 0.005 & 7.3 & $1.8-29.5$ \\
$\quad$ Intraventricular haemorrhage & 3.312 & 0.75 & $<0.001$ & 27.4 & $6.3-119.4$ \\
$\quad$ Volume of haemorrhage $\left(>100 \mathrm{~cm}^{3}\right)$ & 1.766 & 0.68 & 0.010 & 5.9 & $1.5-22.6$ \\
\hline
\end{tabular}

${ }^{\star}$ Motricity Index score 0-50 (normal = 100). SE = standard error.

univariate analysis, which predicted death within 28 days of onset of PICH.

\section{Discussion}

The present study sought to overcome problems encountered in many previous epidemiological studies of PICH by being prospective in design, based on a defined population, and including detailed case finding procedures with an accurate diagnosis of PICH. We found that the proportional frequency $(11 \%)$ of PICH among all subtypes of stroke, and annual incidence (total event) rate of between 24 to 46 per 100000 for PICH in Perth, is similar to that reported in other predominantly Caucasion population based studies. ${ }^{18}$ It is difficult to draw firm conclusions about the age-incidence curves for the sexes because the confidence intervals for the age and sex specific rates were wide and overlapped. The trends were for rates to generally increase with age, however. An early peak in the rates for men in the age group 65-74 years was also found in Finland. ${ }^{18}$ Whereas this is consistent with chance variation, it is interesting to speculate whether there were two different pathological bases for PICH that have different age-incidence curves in men but similar ones in women.

Among the different sites for the origin of haemorrhage, the proportional frequencies of cerebellar (10\%) and brainstem (7\%) haemorrhages are also relatively uniform among studies, but there are important differences in the frequencies of deep compared with lobar haemorrhages. We found a lower frequency of deep $(30 \%)$ haemorrhages compared with other studies, where the figures range from $40 \%{ }^{5}$ to $69 \% .^{12}$ Whereas the frequency and timing of CT are two obvious explanations for this variation, another is differences in case mix. As patients with large deep haemorrhages are often comatose at presentation, ${ }^{25}$ these types of PICH are disproportionately represented in hospital based studies. Another difficulty in comparison of studies is the range of differences in the criteria used to define the site of haemorrhage. We chose to include a category of massive cortical haemorrhage because of the recognised difficulty in defining the origin of haemorrhage in a certain subset of cases. ${ }^{3}$ Even so, the proportional frequency of lobar haemorrhage $(32 \%)$ in Perth was similar to that in a study in Finland (34\%), ${ }^{18}$ but different from studies in Dijon $(19 \%)^{17}$ and Cincinnatti $(40 \%)^{5}$ that did not use this classification system. Although a true differ- ence in the proportional frequency of lobar PICH cannot be excluded, we suspect that much of this wide variation reflects differences in the degree to which studies register nonfatal, non-hospital cases.

The clinical syndrome of PICH depends on the localisation of the haematoma. Few symptoms and signs, however, accurately differentiate haemorrhage from infarction in life. Large infarcts can mimic the classical picture of intracerebral haemorrhage that includes the presence of headache, vomiting, meningism, and early lapse of the patient into coma. Conversely, lobar or small deep haemorrhages can mimic infarction, even including one of the classical lacunar syndromes, or be preceded by transient ischaemic attacks. Therefore, until the risk-benefit ratio of antithrombotic treatment is clearly established, it seems prudent to postpone such treatment in patients with acute stroke until CT has excluded PICH.

Some studies have suggested that hypertension is more likely to be present and implicated as the aetiology of PICH when the haemorrhage is deep rather than lobar, and that among the elderly, amyloid angiography is a more important cause of $\mathrm{PICH}$ than hypertension. ${ }^{4}{ }^{6} \mathrm{We}$ found no difference in the prevalence of hypertension between the different sites of PICH, although we recognise that the retrospective assessment of hypertension is difficult, and hypertensive vasculopathy and amyloid angiopathy may coexist in the same patient. Although systemic neuropathological correlation of the clinical features is highly desirable to clarify the precise role of amyloid angiopathy in the pathogenesis of PICH, this study exemplifies the low yield (only two confirmed cases) from necropsy data. Small lobar haemorrhages carry a low mortality and there are logistical difficulties with long-term follow up of elderly patients.

In this population, recent heavy alcohol consumption emerged as an important risk factor for PICH, whereas cerebrovascular sequelae of use of amphetamines and other illicit drugs seem rare. Alcohol has been shown to increase the risk of both haemorrhagic (PICH and subarachnoid haemorrhage) and ischaemic stroke. ${ }^{25-28}$ Although numerous mechanisms exist by which heavy use of alcohol may predispose to stroke, ${ }^{29}$ those particularly relevant to PICH include raised blood pressure and its inhibitory effects on platelet function. It was interesting that our four cases who presented after an alcoholic binge were all hypertensive at onset, but only one patient required long-term antihypertensive treatment. We cannot exclude undiagnosed amyloidosis or cryptic angiomas as a cause of a small proportion of our cases.

A high fatality is associated with $\mathrm{PICH}$, with most deaths occurring within the first few days of onset. The most important predictors of early mortality are the site and extent of PICH, which are reflected in three simple clinical variables: loss of consciousness, paresis, and incontinence. In common with other studies, volume of haemorrhage and 
presence of intraventricular extension of haemorrhage were also associated with a poor outcome. ${ }^{18}$ 30-32 Cerebellar haemorrhage carried the best prognosis in terms of disability free survival.

Despite the heterogeneity and high mortality of PICH, it remains a major diagnostic and therapeutic challenge to clinicians. Although this study supports the importance of avoidable risk factors such as hypertension and heavy alcohol consumption in the aetiology of $\mathrm{PICH}$, further work needs to be directed at establishing the exact relation between hypertensive vasculopathy, amyloid angiopathy, small vascular anomalies, and iatrogenic factors. Once PICH has occurred, early operative intervention may be beneficial. Clinical trials of such treatment could use simple clinical variables such as level of consciousness, size and site of haematoma, and the presence of intraventricular extension of haemorrhage as a guide to prognosis and stratification.

We are grateful for the support of the National Health and Medical Research Council, the Australian Brain Foundation, and the Royal Perth Hospital Medical Research Foundation. We thank Professor Byran Kakulas, Department of Neuropathology, Royal Perth Hospital, for his support in the study. The study wa Association of Neurologists' Annual Scientific Meeting, Cairns, Australia, July 1993.

1 Fisher CM. Pathological observations in hypertensive cerebral hemorrhage. $₹$ Neuropathol Exp Neurol 1971; 30:536-50.

2 Caplan L. Intracerebral hemorrhage revisited. Neurology 1988;38:624-7.

3 Molinari GF. Lobar hemorrhages. Where do they come from? How do they get there? Stroke 1993;24:523-6.

4 Drury I, Whisnant J, Garraway WM. Primary intracerebra hemorrhage: impact of CT on incidence. Neurolog 1984;34:653-7.

5 Broderick J, Brott T, Tomsick T, Leach A. Lobar hemorrhage in the elderly: the undiminishing importance of hypertension. Stroke 1993;24:49-51.

6 Ueda K, Hasuo Y, Kiyohara Y, et al. Intracerebral hemorrhage in a Japanese community, Hisayama: incidence, changing pattern during long-term follow-up, and changing pattern during long-term

7 Kase CS. Intracerebral hemorrhage. In: Bradley WG Daroff RB, Fenichel GM, Marsden CD, eds. Neurology in clinical practice. Boston: Butterworth-Heinemann, in clinical practic

8 Mohr JP, Caplan LR, Melski JW, et al. The Harvard Cooperative Stroke Registry: a prospective registry Neurology 1978;28:754-62.

9 Kunitz SC, Gross CR, Heyman CS, et al. The pilot stroke data bank: definition, design, and data. Stroke 1984;15: 740-6.

10 Yatsu FM, Becker C, McLeroy KR, et al. Community hospital-based stroke programs: North Carolina, Oregon, and New York. I: Goals, objectives and data collection procedures. Stroke 1986;17:276-84.
11 Bogousslavsky J, Van Melle G, Regli F. The Lausanne stroke registry: analysis of 1000 consecutive patient with first stroke. Stroke 1988;19:1083-92.

12 Chambers BR, Donnan GA, Bladin PF. Patterns of stroke: an analysis of the first 700 consecutive admissions to the Austin Hospital stroke unit. Aust NZ $\mathcal{G}$ Med 1983;13: 57-64.

13 Leftovitz J, Davis SM, Rossiter SC, et al. Acute stroke outcome: effects of stroke type and risk factors. Aust NZ 7 Med 1992;22:30-5.

14 Anderson CS, Jamrozik KD, Burvill PW, Chakera TMH Johnson GA, Stewart-Wynne EG. Determining the incidence of different subtypes of stroke: results from the dence of different subtypes of stroke: results from the Perth community

15 Broderick JP, Phillips SJ, Whisnant JP, O'Fallon WM, Bergstralh EJ. Incidence rates of stroke in the eighties: the end of the decline in stroke? Stroke 1989;20:577-82.

16 Bamford J, Sandercock P, Dennis M, Burn J, Warlow C. A prospective study of acute cerebrovascular disease in the community: the Oxfordshire community stroke project: 1981-86. F Neurol Neurosurg Psychiatry 1990;53:16-22.

17 Giroud M, Grass P, Chadan N, et al. Cerebral haemorrhage in a French prospective population study. $\mathcal{F}$ Neuro Neurosurg Psychiatry 1991;54:595-8.

18 Fogelholm R, Nuutila $M$, Vuorela AL. Primary intracerebral haemorrhage in the Jyuaskyla region, Central Finland, 1985-89: incidence, case fatality rate, and functional outcome. $\mathcal{F}$ Neurol Neurosurg Psychiatry 1992; 55:546-52.

19 Anderson CS, Jamrozik KD, Burvill PW, Chakera TMH, Johnson GA, Stewart-Wynne EG. Ascertaining the true incidence of stroke: results from the Perth community stroke study, 1989-1990. Med F Aust 1993;158:80-4.

20 WHO MONICA Project principal investigators. The World Health Organisation MONICA Project (monitoring trends and determinants in cardiovascular disease)a major international collaboration (prepared by $\mathrm{H}$ Tunstall-Pedoe). $\mathcal{f}$ Clin Epidemiol 1988;41:105-14

21 Teasdale G, Murray G, Parker L, Jennet B. Adding up the Glasgow coma scale. Acta Neurochir (Wien) 1979 28(suppl): 13-6.

22 Demeurisse G, Demol O, Robaye E. Motor evaluation in vascular hemiplegia. Eur Neurol 1980;19:382-9.

23 Wade DT, Collin C. The Barthel ADL index: a standard measure of physical disability? International Disability measure of physical

24 Waterhouse J, Muir C, Correa P, Powell J. Cancer incidence in five continents Vol 3. Lyon: IARC, 1976:456.

25 Melo TP, de Mendonca A, Crespo M, Caralho M, Ferro JM. An emergency room-based study of stroke coma. Cerebrovasc Dis 1992;2:93-101.

26 Donahue RP, Abbott RD, Reed DM, Yano K. Alcohol and hemorrhagic stroke: the Honolulu Heart Program. ЭAMA 1986;255:2311-4

27 Stampfer MJ, Colditz GA, Willett WC, Speizer FE, Hennekens $\mathrm{CH}$. A prospective study of moderate alcohol consumption and the risk of coronary disease and stroke in women. N Engl F Med 1988;319:267-73.

28 Gill JS, Shipley MJ, Tsementzis SA, et al. Alcohol consumption-A risk factor for hemorrhagic and nonhemorrhagic stroke. Am $f$ Med 1991;90:489-97.

29 Gorelick PB. The status of alcohol as a risk factor for stroke. Stroke 1989;12:1607-10.

30 Tuhrim S, Dambrosia J, Price $\mathrm{T}$, et al. Intracerebral hemorrhage: external validation and extension of a model for predicti

31 Daverat P, Castel JP, Dartigues JF, Orgogozo JM. Death and functional outcome after spontaneous intracerebral hemorrhage: a prospective study of 166 cases using multivariate analysis. Stroke $1991 ; 11: 1-6$.

32 Broderick JP, Brott TG, Duldner JE, Tomsick T, Huste $G$. Volume of intracerebral hemorrhage: a powerful and easy-to-use predictor of 30-day mortality. Stroke 1993; 